\title{
Cytokine Hemoadsorption in the Management of a Pregnant Woman with COVID-19 Pneumonia: Case Report
}

\author{
Esra Sultan Karabulut Keklik ${ }^{1} \cdot$ Hakan Dal $^{1} \cdot$ Şahin Bozok ${ }^{2}$ (D)
}

Accepted: 7 September 2020 / Published online: 16 September 2020

(C) Springer Nature Switzerland AG 2020

\begin{abstract}
Here, we discussed a 22-year-old pregnant woman (gestational age: 32 weeks) infected with COVID-19 who presented with fever $\left(39.1^{\circ} \mathrm{C}\right)$ and respiratory symptoms. Thoracic computed tomography could not be obtained due to pregnancy. PCR testing was positive. The patient was treated with supportive care and anti-viral and anti-inflammatory agents; however, general health status deteriorated and patient was admitted to intensive care unit on day 3. After admission to COVID-19 ICU, clinical picture was rapidly worsened with development of respiratory failure and acute respiratory distress syndrome (ARDS). Thus, "extracorporeal cytokine hemoadsorption" (CytoSorb®, Cytosorbents Corporation, Monmouth Junction, NJ, USA) was planned and performed with regular intervals in order to remove inflammatory cytokines from circulation and to relieve systemic inflammatory response. The fever response and CRP elevation were controlled by hemoadsorption and cytokine filter performed in alternate days. On day 7 of ICU admission, it was decided to terminate pregnancy due to worsening hypoxemia and a healthy, premature infant was born. On day 2 after cesarean section, the patient was intubated and mechanical ventilation support was initiated. However, the patient showed an increasingly complicated clinical course and died on day 22 after ICU admission. It is seen that COVID-19 positivity carries an important risk for both mother and fetus, particularly in those at advanced stages of gestation, by physiological changes in the mother during pregnancy. We believe that, in the treatment of COVID-19 and its complications during pregnancy, cytokine filter treatment can give time to patient for hemodynamic and metabolic stabilization.
\end{abstract}

Keywords COVID-19 · Pregnant woman · Coronavirus · Pneumonia · Complication · Cytokine hemoadsorption · Cytokine storm

\section{Introduction}

The novel coronavirus (nCOV-2019) was first identified in Wuhan Province, China, on December 2019 and it was declared as a pandemic on February 2020 by the World Health Organization [1-3]. Since then, it has remained as an important health problem worldwide. Cytokine storm has an important role in the disease severity $[4,5]$. Clinical spectrum ranges from asymptomatic infection to severe pneumonia and may result in ICU admission [1-3].

This article is part of the Topical Collection on COVID-19

Șahin Bozok

sahinboz@yahoo.com

1 Department of Anesthesiology and Reanimation, Ușak Training and Research Hospital, Ușak, Turkey

2 Department of Cardiovascular Surgery, Usak University, Faculty of Medicine, Fevzi Çakmak Mahallesi Denizli Caddesi No:4 64100 Merkez, Ușak, Turkey
The hemodiafiltration, which has become an important therapeutic modality in ICU patients with acute renal insufficiency, is also used to remove inflammatory mediators in extra-renal settings [6]. The well-known examples of hemodiafiltration use for extra-renal causes are systemic inflammatory response syndrome, sepsis, and other inflammatory syndromes. In such cases, it is aimed to remove inflammatory cytokines from circulation by hemodiafiltration and reduce systemic inflammatory response. However, in previous studies, cytokine clearance from circulation by hemodiafiltration has not been proven in septic patients [6].

It has been reported that COVID-19 pneumonia is more commonly seen in male gender with limited number of pediatric cases [7]. The pregnant women are more vulnerable to infection due to suppressed in immunity. Given the alterations in maternal physiological and immune functions during pregnancy, the risk for SARS-CoV-2 infection may be higher and clinical presentation may be more complicated in pregnant women. To contribute understanding in pregnant patients, we aimed to present a 22 years pregnant woman (gestational 
age: 32 weeks) with complicated COVID-19 disease who underwent extra-corporal cytokine hemoadsorption therapy.

\section{Case Report}

A 22-year-old pregnant woman (gestational age: 32 weeks) without known systemic disease presented to our hospital with fever. The patient declined CT imaging as she was pregnant. The pregnant woman without respiratory, circulatory, and metabolic problem requiring intensive care unit admission was admitted to a pandemic clinic with suspected COVID-19. As PCR test was positive in the patient, hydroxychloroquine $(2 \times$ $400 \mathrm{mg}$ loading dose followed by $2 \times 200 \mathrm{mg}$ maintenance dose $)$ and azyrthromycin $(2 \times 500 \mathrm{mg}$ loading dose followed by $2 \times 250 \mathrm{mg}$ maintenance dose) was prescribed based on the National Treatment Guideline [8].

On day 3 after admission, the patient had hypoxemia (peripheral oxygen saturation: $80 \%$ ) and tachypnea (respiration rate: $36 / \mathrm{min}$ ); thus, she was admitted to the pandemic intensive care unit.

At ICU admission, the patient was conscious and peripheral oxygen saturation was $78 \%$ during spontaneous breathing under oxygen supplementation $(6-8 \mathrm{~L} / \mathrm{min})$ via face mask. The vital signs at ICU admission were as follows: blood pressure, $140 / 80 \mathrm{mmHg}$; heart rate, $140 / \mathrm{min}$, body temperature, $40{ }^{\circ} \mathrm{C}$. Non-invasive mechanical ventilation was initiated (via full-face mask; pressure-assisted ventilation mode; PEEP: 7 $\mathrm{cmH}_{2} \mathrm{O}$ and $\mathrm{PS}: 14 \mathrm{cmH}_{2} \mathrm{O} ; 50 \%$ oxygen supplementation) in the patient. Peripheral oxygen saturation was improved to $97 \%$ and tachypnea was decreased (respiration rate: $24 / \mathrm{min}$ ). The patient was consulted to Obstetrics \& Gynecology Department; given the fact that non-stress test revealed no abnormal sign and that there was an improvement in hypoxemia by non-invasive mechanical ventilation, it was planned to monitor fetus closely for pulmonary development without termination of pregnancy.

In the patient with positive PCR testing for COVID-19, cytokine storm was considered due to findings of fever, tachypnea, tachycardia, hypoxemia, and C-reactive protein (CRP) elevation. Ritonavir (50 mg, PO) plus lopinavir (200 mg, $2 \times 2 \mathrm{PO}$ ) was added to initial treatment with hydroxychloroquine ( $200 \mathrm{mg}$ tablets, $2 \times 1)$. Since the patient declined radiological imaging studies, no chest radiography or pulmonary CT scan could be performed. Thus, lung sonography was planned to the patient. However, owing to the settings of COVID-19 ICU, general health status of patient, and inexperience, an adequate assessment could not be performed. Although routine treatment protocols in COVID-19 disease are not included, methyl prednisolone $(40 \mathrm{mg})$ was initiated for fetal lung development (32 weeks of gestation).

Tociluzimab (interleukin-6 antagonist) therapy with pregnancy category $\mathrm{C}$ due to lack of sufficient evidence [9] and interleukin-1 antagonist due to problems in availability of drug was not given to the patient who was considered as cytokine storm based on clinical and laboratory findings. Thus, extra-corporal cytokine hemoadsorption therapy was performed to remove inflammatory cytokines from circulation and to reduce systemic inflammatory response. Fever response and CRP elevation were controlled by hemoadsorption and cytokine filter $\left(\right.$ CytoSorb ${ }^{\circledR}$, Cytosorbents Corporation, Monmouth Junction, NJ, USA) performed on every other day. Table 1 presents daily clinical and laboratory data. During follow-up, interleukin-6 could not be monitored due to unavailability of IL-6 kits in our hospital during pandemic.

On day 7 after ICU admission, the patient underwent cesarean section based on NST and obstetric sonography findings and deterioration in hypoxemia. The Apgar scores on minute 1 and 5 were 3 and 9 , respectively; thus, a short-term ( $2 \mathrm{~min}$ ) neonatal resuscitation was provided. It was found that 2 consecutive PCR tests were negative for COVID-19 in the infant; thus, newborn was discharged after 7 days of intensive care admission for prematurity-related problems.

After cesarean section, extra-corporal cytokine hemoadsorption therapy with cytokine filter was repeated due to anticipation of worsening cytokine storm following surgery.

Low-molecular weight heparin prophylaxis was given as of admission to ICU. Initial prophylactic enoxaparin dose ( $0.4 \mathrm{IU} / \mathrm{mL})$ was up-titrated to $0.8 \mathrm{IU} / \mathrm{mL}$ on day 4 after ICU admission by monitoring D-dimer levels.

The high-flow nasal oxygen supplementation $\left(37^{\circ} \mathrm{C} ; 60 \mathrm{~L} /\right.$ min flow and $40 \%$ oxygen) and interrupted non-invasive mechanical ventilation $\left(50 \%\right.$ oxygen; PEEP: $7 \mathrm{cmH}_{2} \mathrm{O}$; Psupport: $14 \mathrm{cmH}_{2} \mathrm{O}$; pressure-assisted ventilation mode, via oronasal mask) were applied until day 2 after cesarean section.

On day 2 after cesarean section, orotracheal intubation was performed and mechanical ventilation was initiated; the patient was placed to prolonged prone position $(22 \mathrm{~h})$ due to worsened gas exchange (P/F: 70). During follow-up, Acinetobacter sepsis, deep venous thrombosis in left femoral vein, and subsequent pulmonary embolism were developed in the patient and he patient died on day 22 after ICU admission despite all efforts.

\section{Discussion}

SARS-CoV-2 is a positive, single-strand RNA virus [1-3]. The SARS-CoV-2 gains access to cell via ACE-2 receptor; it was reported that target cells include type II alveolar cells, myocardial cells, renal proximal tubule cells, epithelial cells of ileum and esophagus, and urothelial cells in bladder $[5,10]$.

Cytokines have an important role in naïve immune system. The cytokine storm is uncontrolled release of cytokines that may be triggered by several factors such as viral and bacterial components, sepsis, super-antigens, toxins, and antibodies 


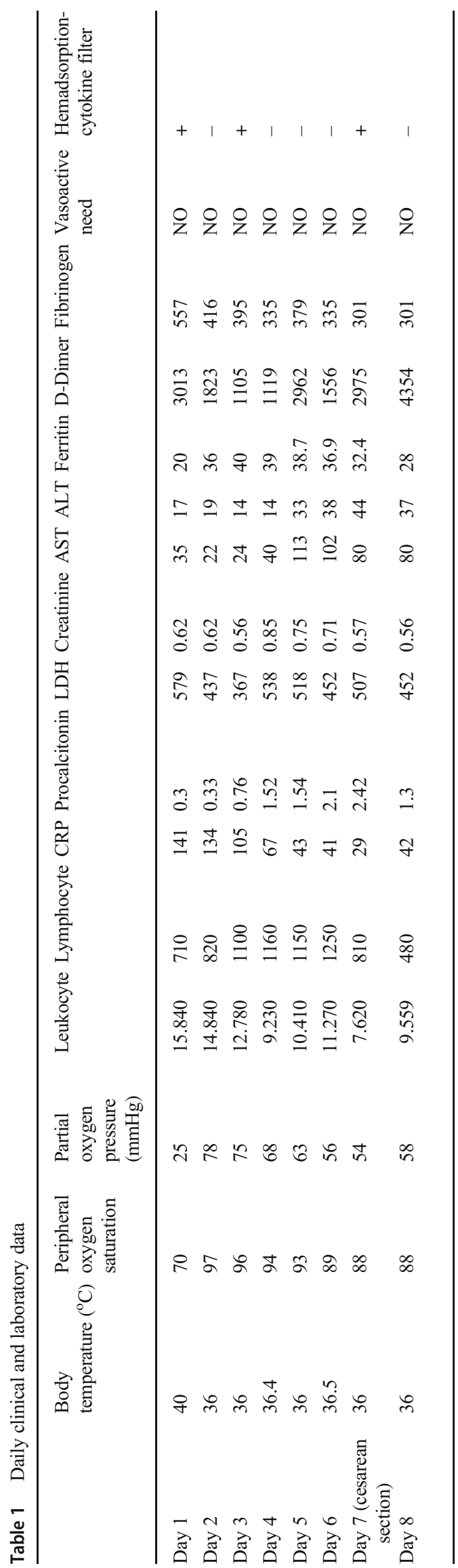

[11]. Data from China suggest that SARS-CoV-2 virus can induce cytokine storm depending on disease severity [11]. However, lymphocytopenia is not considered as risk factor associated to cytokine storm and disease severity [11].

Although there is additional organ failure in $67 \%$ of critically ill COVID-19 patients, it has been reported that this is due to a sepsis-like condition progressing with elevated cytokine levels [12]. Extra-corporal blood purification technique has been recommended in critically ill patients with sepsis or sepsis-like syndromes [13]; Cytosorb cartridges are among these techniques and include biocompatible, polystyrenedivinylbenzene copolymer beads which can adsorb middlemolecular weight molecules using a combination of molecular weight and hydrophobic interactions [13]. It can be used either alone (hemoperfusion) or as a parallel circuit attached to renal replacement therapy circuit, cardiopulmonary bypass system, or extra-corporal membrane oxygenation circuit. The Cytosorb can remove several molecules from circulation such as pro- and anti-inflammatory cytokines, bilirubin, myoglobin, exotoxins, and drugs [14].

In case of cytokine storm, persistent fever, hepatic dysfunction, hepatomegaly, coagulopathy, skin eruption, and neurological symptoms are present [15]. In severe disease induced by SARS-CoV, IL-6 levels are markedly high [15]. We also used Cytosorb-cytokine filter attached parallel to continuous renal replacement circuit considering cytokine storm based on presence of persistent fever, elevated CRP level, hypoxemia, and lymphopenia in a patient with confirmed COVID-19 disease. In our patient, IL-6 level could not be monitored due to problems in availability of test kits caused by the pandemic. The treatment was monitored by clinical response (regression in fever and hypoxemia level) and CRP level. Based on these parameters, good clinical response after procedure and reduction in CRP levels suggested that cytokine hemoadsorption can be beneficial in cytokine storm.

Although COVID-19 disease is asymptomatic or associated with mild symptoms in majority of cases, severe complications, organ failure, and even death can occur. The present outbreak requires intensive care in 5\% of infected population and mortality rate is reported as approximately $49 \%$ in critically ill patients [12]. The outbreak remains to be a major health problem and there is no specific vaccine against disease. Given data reported so far, it was seen that the disease has a fatal course in patients with advanced age or comorbid conditions such as coronary artery disease, diabetes mellitus while male gender is affected more commonly, and pregnancy has no influence on severity of disease [16]. In our case, presence of a fetus (gestational age: 32 weeks), not using drugs such as favipiravir with marked effectiveness during time period until extraction of fetus, and cesarean section indication due to hypoxemia and postpartum period made clinical course more complicated. In this case, pulmonary embolism, pneumosepsis, femoral vein thrombosis, pulmonary 
thromboembolism, and spontaneous pneumothorax prolonged length of ICU stay and days in mechanical ventilation.

In a Chinese study including 13 pregnant women with COVID-19 disease, the most common symptom was reported as fever. The age ranged from 28 to 36 years; 11 of 13 pregnant women were in third trimester; one patient in third trimester was admitted to ICU with acute respiratory distress syndrome and multiple organ failure during follow-up. The frequency of ICU admission was reported to be comparable to general population [17]. During pandemic period, 4 pregnant women were treated in our hospital. All patients were treated in accordance with the National Treatment Guidelines [8]. Of these, 3 pregnant women were discharged successfully; however, the patient presented in this paper died.

In 1918 flu pandemic, it was reported that mortality rate was $2-6 \%$ in general population and $37 \%$ in pregnant women [15]. In $2009 \mathrm{H} 1 \mathrm{~N} 1$ influenza pandemic, it was seen that complication rate was increased in pregnant women and hospitalization rate was higher when compared with general population [18]. In a study by Wong et al., it was reported that 50\% of pregnant women with SARS were admitted to ICU and that $33 \%$ required mechanical ventilation with mortality rate of $25 \%$ [19]. In a study by Chen et al., it was reported that, in pregnant women, clinical characteristics of COVID-19 pneumonia were similar to non-pregnant adults [20]. No ICU admission was required in 9 pregnant women in the study. Although the disease course became complicated due to sepsis, pneumothorax, and thromboembolism in our case, we believe that there is no sufficient data in pregnant women.

There are some limitations about this case. First of all, during cytokine hemoadsorption, a hemodialysis catheter is necessary, so this can cause some complications such as infection, trombosis. Another limitation about this case IL-6 did not monitorized. COVID-19 treatment protocols are still unclear, although it is not appropriate to comment on a single case, we wanted to share our experience in a complicated pregnant woman with COVID-19 pneumonia with this case report. Some new membrane technologies targeting cytokine removal may result in better outcomes. There may be a "window of opportunity" for patients with severe COVID-19, and early application of blood purification therapies should be considered.

\section{Conclusion}

We think that COVID-19 positivity comprises great risk for both mother and fetus in pregnant women with gestational age due to physiological maternal changes. Although it has been reported that the course of COVID-19 disease was similar to the general population in pregnant women, maternal and fetal death are also seen. Although there are limitations in the treatment of COVID-19 and its complications (favipiravir has not been studied in pregnant women), cytokine filter can buy extra time for hemodynamic and metabolic stabilization.

\section{Compliance with Ethical Standards}

Conflict of Interest The authors declare that they have no conflicts of interest.

Informed Consent The legally authorized representative of the patient has given her consent for the publication of this article.

\section{References}

1. Yilmaz Y, Kamer E. Planning and safety of surgical operation in COVID-19 pandemic. Ege Klin Tip Derg. 2020;58(1):55-61.

2. Kamer E, Çolak T. What to do when a patient infected with COVID-19 needs an operation: a pre-surgery, peri-surgery and post-surgery guide. Turk J Colorectal Dis. 2020;30:1-8. https:// doi.org/10.4274/tjcd.galenos.2020.2020-3-7.

3. Mavioğlu HL, Ünal EU, Așkın G, Küçüker ŞA, Özatik MA. Perioperative planning for cardiovascular operations in the COVID-19 pandemic. Turk Gogus Kalp Dama. 2020;28:236-43. https://doi.org/10.5606/tgkdc.dergisi.2020.09294.

4. Zhou G, Chen S, Chen Z. Advances in COVID-19: the virus, the pathogenesis, and evidence-based control and therapeutic strategies. Front Med. 2020;14(2):117-25. https://doi.org/10.1007/ s11684-020-0773-x.

5. Göçer H, Durukan AB. ACE-gene polymorphism, particularly " $D /$ I", may play a role in the occurrence of COVID-19 pneumonia in hypertensive elderly patients. Cardiovasc Surg Int. 2020;7(1):39. https://doi.org/10.5606/e-cvsi.2020.779.

6. Schetz MR. Classical and alternative indications for continuous renal replacement therapy. Kidney Int Suppl. 1998;66:129-32.

7. Chen N, Zhou M, Dong X, et al. Epidemiological and clinical characteristics of 99 cases of 2019 novel coronavirus pneumonia in Wuhan, China: a descriptive study. Lancet. 2020;395(10223): 507-513. doi: https://doi.org/10.1016/S0140-6736(20)30211-7.

8. T.C. Sa ğ $l_{1} \mathrm{k}$ Bakanl $\breve{g}_{1}$ COVID-19 (SARS-CoV-2 ENFEKSIYONU) REHBERİ; sayfa: 53, Erișim adresi:https:// covid19bilgi.saglik.gov.tr/depo/rehberler/COVID-19_Rehberi.pdf

9. Pham T, Claudepierre P, Constantin A, de Bandt M, Fautrel B, Gossec L, et al. Tocilizumab: therapy and safety management. Joint Bone Spine. 2010;77(Suppl 1):S3-S100.

10. Hoffmann M, Kleine-Weber H, et al. SARS-CoV-2 cell entry depends on ACE2 and TMPRSS2 and is blocked by a clinically proven protease inhibitor. Cell 2020 Mar 4. [Epub ahead of print] https:// doi.org/10.1016/j.cell.2020.02.05218.

11. Lu R, Zhao X, Li J, et al. Genomic characterisation and epidemiology of 2019 novel coronavirus: implications for virus origins and receptor binding. Lancet. 2020;395(10224):565-74.

12. Ronco C, Reis T, De Rosa S. Coronavirus epidemic and extracorporeal therapies in intensive care: si vis pacem para bellum. Blood Purif. 2020;49(3):255-8. https://doi.org/10.1159/000507039 Epub 2020 Mar 13.

13. Poli EC, Rimmelé T, Schneider AG. Hemoadsorption with CytoSorb®. Intensive Care Med. 2019;45(2):236-9. https://doi. org/10.1007/s00134-018-5464-6 Epub 2018 Nov 16.

14. Malard B, Lambert C, Kellum JA. In vitro comparison of the adsorption of inflammatory mediators by blood purification devices. Intensive Care Med Exp. 2018;6:12. 
15. Behrens EM. Cytokines in cytokine storm syndrome. In: Cron RQ, Behrens EM, editors. Cytokine Storm Syndrome. Cham: Springer International Publishing; 2019. p. 197-207.

16. Organization WH. Rolling updates on coronavirus disease (COVID-19). https:// wwwwhoint/emergencies/diseases/novel-coronavirus-2019/events-as-theyhappen, Accessed date: 24 March 2020.

17. Liu Y, Chen H, Tang K, Guo Y. Clinical manifestations and outcome of SARS-CoV-2 infection during pregnancy. J Infect 2020. https://doi.org/10.1016/j.jinf.2020.02. 028. Published online March 4.

18. Jamieson DJ, Honein MA, Rasmussen SA, Williams JL, Swerdlow DL, Biggerstaff MS, et al. H1N1 2009 influenza virus infection during pregnancy in the USA. Lancet. 2009;374:451-58.10.
19. Wong SF, Chow KM, Leung TN, Ng WF, Ng TK, Shek CC, et al. Pregnancy and perinatal outcomes of women with severe acute respiratory syndrome. Am J Obstet Gynecol. 2004;191:292-7.

20. Chen H, Guo J, Wang C, et al. Clinical characteristics and intrauterine vertical transmission potential of COVID 19 infection in nine pregnant women: a retrospective review of medical records. Lancet. 2020;395(10226):809-15. https://doi.org/10.1016/S01406736(20)30360-3 Epub 2020 Feb 12.

Publisher's Note Springer Nature remains neutral with regard to jurisdictional claims in published maps and institutional affiliations. 